\title{
A arterapia e o desenvolvimento do comportamento no contexto da hospitalização*
}

\author{
ART THERAPY AND BEHAVIOR DEVELOPMENT IN THE CONTEXT OF HOSPITALIZATION \\ ELARTETERAPIA Y EL DESARROLLO DEL COMPORTAMIENTO EN \\ EL CONTEXTO DE LA HOSPITALIZACIÓN
}

Ana Cláudia Afonso Valladares' ${ }^{1}$, Ana Maria Pimenta Carvalho²

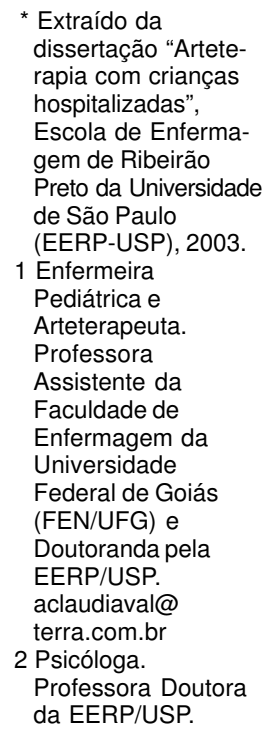

\begin{abstract}
RESUMO
A hospitalização pode ter efeitos negativos sobre o desenvolvimento e comportamento infantil. Assim, objetivou-se avaliar, neste trabalho, o comportamento de crianças com idade de 7 a 10 anos internadas, antes e após intervenção de arteterapia. Utilizouse, para esse fim, um esquema quasi-experimental com grupo controle $(n=10)$ e um grupo experimental $(n=10)$. Os resultados mostraram que as intervenções de arteterapia foram eficazes, por promoverem a melhoria das respostas comportamentais de seus participantes. Conclui-se, então, que os hospitais podem ser ambientes estimulantes para a criança, implementando práticas de cuidados para além da doença.
\end{abstract}

\section{DESCRITORES}

Terapia pela arte.

Comportamento infantil.

Criança hospitalizada.

\begin{abstract}
Hospitalization may have negative effects on child development and behavior. Thus the aim of this work was to evaluate the behavior during the hospitalization of 7- to 10-year old children, before and after art therapy intervention. It was proposed a quasi-experimental plan with a control group $(n=10)$ and a group that was submitted to art therapy intervention $(n=10)$. Results show that these interventions were effective in improving the behavior of the children. Hospitals can also be stimulating environments for children if they offer them health care practices that go beyond the disease.
\end{abstract}

\section{KEY WORDS}

Art therapy.

Child behavior.

Child, hospitalized.

\section{RESUMEN}

La hospitalización puede tener efectos negativos sobre el desarrollo y comportamiento infantil. Así, se tuvo como objetivo evaluar, en este trabajo, el comportamiento de niños con edad de 7 a 10 años internados, antes y después de la intervención de la arteterapia. Se utilizó, para este fin, un esquema cuasiexperimental con grupo control $(n=10)$ y un grupo experimental $(n=10)$. Los resultados mostraron que las intervenciones de arteterapia fueron eficaces, por promover la mejora de las respuestas de comportamiento de sus participantes. Se concluyó, entonces, que los hospitales pueden ser ambientes estimulantes para el niño, implementando prácticas de cuidados para más allá de la enfermedad.

\section{DESCRIPTORES}

Terapia con arte.

Conducta infantil.

Niño hospitalizado. 


\section{INTRODUÇÃO}

No contexto da arteterapia, as modalidades de expressão não-verbais assumem grande importância na relação terapeuta-criança, uma vez que o comportamento revela alguns sinais da comunicação não-verbal da criança expressos pelo corpo, como: postura, olhar, orientação dos gestos e movimentos corporais, expressão emocional, expressão facial, aproximação ou distanciamento do espaço pessoal e conduta tátil ${ }^{(1)}$. Como linguagem não-verbal, os sinais paralingüísticos, expressos pela entonação de voz e pela velocidade de pronúncia, entre outros, são importantes de serem analisados como expressão do pensamento ao lado da comunicação verbal (palavras) $)^{(1)}$.

Assim, o estudo do não-verbal favorece a capacidade do profissional de saúde de perceber com maior nitidez sentimentos do cliente, suas dúvidas e dificuldades de verbalização, ademais, auxilia potencializar sua própria comunicação, enquanto elemento transmissor de mensagens ${ }^{(1)}$.
O desenvolvimento infantil é um processo complexo, que envolve as diferenças individuais e as específicas de cada período, como mudanças nas características, nos comportamentos, nas possibilidades e limitações de cada fase da vida, indistintamente. Por isso, a singularidade das crianças lhes é conferida por influências de seu ritmo próprio de desenvolvimento e por características pessoais que as diferenciam das demais ${ }^{(4)}$.

O período que vai de sete aos dez anos de idade, objeto de estudo deste trabalho, e que se convencionou chamar de escolar, é decisivo para a estruturação harmoniosa do indivíduo $^{(8)}$. Nesta etapa, ocorrem transformações significativas na vida da criança, abrangendo os aspectos cognitivos, socioemocionais e da comunicação plástica, quando seu raciocínio fica mais lógico e passa a compreender melhor os fatos $^{(4)}$; ademais, neste período, amplia suas relações, distanciando-se do convívio familiar, movendo-se em direção ao contexto social e aos grupos de pares, passando a ser menos egocêntrica ${ }^{(8)}$.
Nas intervenções de arteterapia, a predominância é do não-verbal, isto é, a abordagem e as formas de intervenção destinam-se ao confronto com conteúdos inerentes a processos psíquicos primários e pré-verbais. $\mathrm{O}$ arteterapeuta, na intervenção, utiliza a palavra durante o desenrolar dos processos expressivos, não de forma abusiva, pois ela poderá dificultar o aprofundar da psique. Após o término das atividades plásticas, a palavra poderá ser mais produtiva, com o objetivo de melhor expor as experiências subjetivas, de maneira às vezes mais profunda. De qualquer forma, antes ou depois da palavra, com ou sem ela, o indivíduo já terá experimentado dentro de si, algo que efetivamente a arteterapia tem de maior eficácia terapêutica, como: expressar, configurar e materializar conflitos e $\operatorname{afetos}^{(2)}$.

A arteterapia não é mero entretenimento, mas, sim, uma forma de linguagem que permite à pessoa comunicar-se com os outros. Desse modo, possibilita à criança não só a liberdade de expressão, mas também sustenta sua autonomia criativa, ampliando o seu conhecimento sobre o mundo e proporcionando seu desenvolvimento tanto emocional, como social. Por conseguinte, é importante à vida da pessoa, e pode ser de grande valor para aquelas que apresentam patologias diversas e estão hospitalizadas ${ }^{(3)}$.

No caso das crianças, o adoecimento favorece alterações na sua vida, como um todo, podendo, muitas vezes, desequilibrar seu organismo interna e externamente, o qual, em conseqüência disso, gerará um bloqueio no seu processo de desenvolvimento e comportamento saudável, especialmente se a doença for longa ${ }^{(4-7)}$.
O objetivo deste trabalho foi avaliar o comportamento de crianças com idade de sete a dez anos, internadas devido a moléstias infecciosas, antes e após intervenção de arteterapia.

\section{MÉTODO}

Tipo de estudo: as autoras trabalharam com a abordagem quantitativa e delineamento quasi-experimental.

Amostra e local: caracterizaram a amostra vinte crianças internadas no Hospital de Doenças Transmissíveis (HDT) de Goiânia

- Goiás, durante o primeiro semestre de 2003, sendo que dez compuseram o grupo experimental (grupo que passou por intervenções de arteterapia) e outras dez, o grupo controle (grupo que não passou por intervenções de arteterapia). Os grupos foram constituídos por crianças de ambos os sexos, na faixa etária entre sete anos e sete meses a dez anos e onze meses de idade.

Procedimentos: este estudo é parte da dissertação da autora principal, intitulada: "Arteterapia com crianças hospitalizadas", tendo sido aprovado pelo Comitê de Ética em Pesquisa Médica Humana e Animal do HDT. A pesquisadora principal consultou as crianças e seus responsáveis quanto ao desejo de participarem do mesmo, e após sua aquiescência, os responsáveis assinaram o Termo de Consentimento Livre e Esclarecido, conforme as normas de pesquisa com seres humanos - Resolução nº $196 / 96^{(9)}$.

Analisou-se o comportamento das crianças com relação à arteterapeuta e ao material durante as avaliações iniciais (antes do processo arteterapêutico) e finais (após as inter- 
venções de arteterapia), conduzidas em atendimento individualizado, os quais seguiram uma temática padronizada, isto é, a autora principal propôs para o desenvolvimento das avaliações (inicial e final) cinco modalidades artísticas (desenho, pintura, colagem/recorte, modelagem e construção) e na medida em que as crianças construíram seus trabalhos artísticos, estas eram observadas por um auxiliar de pesquisa.

A observação direta e participante, durante as avaliações, foi muito importante para se obter uma avaliação do comportamento em seu contexto situacional, com base em uma descrição sistemática do mesmo na situação "natural" das avaliações (iniciais e finais) e após a observação efetuou-se o registro das mesmas em categorias.

O instrumento empregado para análise dos dados foi a Ficha de Avaliação de Características do Comportamento das Crianças, uma adaptação das escalas do modelo de Machado, Figueiredo \& Selegato ${ }^{(10)}$, que visavam à observação de campo em sala de aula, tendo sido ajustadas para o presente estudo, com o fim de avaliarem os comportamentos dos participantes (crianças) na sua relação com a arteterapeuta e com o material de arte em si (Anexo 1 e 2).

Os itens avaliados em relação à arteterapeuta foram: os níveis de agressividade, tranqüilidade, respeito, obediência, comunicação, rebeldia, tensão, saliência, dependência e controle (Anexo1). Os itens avaliados em relação ao trabalho executado, foram: os níveis de inquietação, impulsividade, organização, aplicação, tensão, saliência, apatia, rapidez, atenção, interesse, participação, orientação, persistência e cuidado (Anexo 2).

Quanto à avaliação dos itens relativos ao comportamento, estes podiam estar presentes ou ausentes na dinâmica da criança, sendo classificados em escores de até cinco pontos, evoluindo de um pólo oposto ao outro.

Um auxiliar de pesquisa, que recebeu treinamento prévio, realizou as observações utilizando esse instrumento, tendo também compartilhado as avaliações com a arteterapeuta.

As intervenções de arteterapia consistiram de acompanhamento individual, realizadas no decorrer de sete sessões, durante três dias e meio consecutivos, com duração variada de uma hora a três horas e meia, cada. Durante as intervenções, trabalharam-se várias modalidades de arte apoiadas às necessidades singulares de cada criança, favorecendo a conduta focal e imediata e reforçando, assim, o vínculo. As intervenções consistiram de técnicas lúdicas e de atividades artísticas, com condução espontânea das dinâmicas, o que favoreceu a exteriorização da subjetividade da criança. Durante as intervenções utilizaram-se várias modalidades expressivas, entre elas, o desenho, a pintura, a colagem, a modelagem, a construção, a gravura, o origami, a dramatização, os jogos educativos e a escrita criativa. d) Análise dos dados: para análise comparativa dos dados, aplicou-se o teste T de Wilcoxon ${ }^{(11)}$ nas duas amostras dependentes. Nos protocolos de avaliação realizados estão contidas pontuações relativas à qualidade dos desempenhos, aos quais atribuíram-se níveis de gradação de pontos na ordem crescente, isto é, do nível inferior para o superior de qualidade. A avaliação geral do comportamento dos grupos (A e B) mostrou um resultado total, considerando-se as dez assertivas sobre o comportamento da criança em relação à arteterapeuta (Anexo 1) e 14 assertivas sobre o comportamento da criança em relação ao material de arte (Anexo 2).

\section{RESULTADOS E DISCUSSÃO}

Com a intenção de verificar a existência ou não de diferenças no comportamento da criança com relação à arteterapeuta e ao material de arte, nas avaliações inicial e final de cada grupo, separadamente, realizaram-se as comparações utilizando o Teste T de Wilcoxon. O Quadro 1 exibe o desempenho dos grupos A (experimental) e B (controle), separadamente, no que diz respeito aos resultados obtidos nas duas modalidades.

Quadro 1 - Comparação intragrupos dos escores obtidos nas avaliações inicial e final, quanto ao comportamento das crianças, em relação à arteterapeuta e material de arte* - Goiânia - 2003

\begin{tabular}{|l|c|c|}
\hline Comportamento da criança & GA & GB \\
\hline Em relação à arteterapeuta & $\mathrm{AI}<\mathrm{AF}^{1}$ & $\mathrm{AI}=\mathrm{AF}$ \\
\hline Em relação ao material de arte & $\mathrm{AI}<\mathrm{AF}^{1}$ & $\mathrm{AI}=\mathrm{AF}$ \\
\hline
\end{tabular}

*Teste T de Wilcoxon ${ }^{(11)}$

$1 \mathrm{p}<0,01$

GA (Grupo A - experimental): $\mathrm{n}=10 \quad$ GB (Grupo B - controle): $\mathrm{n}=10$ AI: avaliação inicial (antes das intervenções de arteterapia)

AF: avaliação final (após as intervenções de arteterapia)

Os dados do comportamento das crianças em relação à arteterapeuta, no Quadro 1, indicam que a maioria dos sujeitos do grupo A (experimental) apresentou progresso significativo da avaliação inicial para a final, por mostrarem maior tranqüilidade, respeito, obediência, comunicação, solicitude, relaxamento, independência e controle, após as intervenções de arteterapia. Em relação ao aspecto de as crianças estarem mais tímidas, não se registraram diferenças significativas nos dois grupos.

Quanto ao grupo B (controle), este na avaliação final não indicou alterações estatisticamente significativas em relação à avaliação inicial, demonstrando pontuações semelhantes nas duas avaliações (inicial e final).

Observa-se, sobretudo, que as categorias que progrediram no grupo A (experimental) referem-se às reações, que 
exigem da criança maior envolvimento com outra pessoa, neste caso a arteterapeuta. As crianças normalmente manifestam defesas cristalizadas, mas através da efetivação de vínculos estas defesas vão se desfazendo. A criança necessita perceber o suporte que existe na situação terapêutica para que, adquirindo confiança, possa relaxar e deixar-se envolver ${ }^{(12)}$.

Os dados desta pesquisa vão ao encontro da concepção de que a intervenção da arteterapia funciona como um momento de descontração e alívio de estresse. A arteterapia serve como calmante ou tranqüilizador, sendo uma medida preventiva ao embotamento psíquico, agindo também como facilitador de competências para a noção de aquisição de esquemas de vida diária ${ }^{(13)}$.

Pesquisando-se os efeitos de um Programa de Ativida$\operatorname{des}^{(14)}$ (que incluía a leitura, a estimulação, o relaxamento e a fantasia) sobre o repertório comportamental de crianças, constatou que, a partir das atividades citadas acima, as do grupo de adesão (experimental) emitiram comportamentos que facilitaram a execução do procedimento médico de inalação, em relação ao outro grupo, que não teve acesso ao Programa. Os resultados dessa pesquisa corroboram os efeitos positivos no comportamento, obtidos a partir das intervenções de arteterapia. Tais resultados são coerentes, também, com as observações de que a ludoterapia oferece às crianças, qualquer que seja sua idade, atividades estimulantes, divertidas e enriquecedoras, trazendo-lhes, ao mesmo tempo, calma e segurança ${ }^{(15)}$.

Ao se propor um trabalho de arteterapia, cria-se a possibilidade de organizar percepções, sentimentos e sensações ${ }^{(16)}$, além do que, a descarga de tensão e o prazer de fazer arte constituem uma maneira menos invasiva de abordar essa clientela ${ }^{(17)}$.

Subsidiando esses dados, pesquisadores ${ }^{(18)}$ argumentam que a atenção afetiva do arteterapeuta direciona a relação que cada pessoa estabelece com a manipulação do material, dos instrumentos e dos movimentos eficazes; assim, afora o resultado propriamente plástico, constata-se o prazer do contato sensorial do sujeito com o material e a manifestação de seus gestos, que transformam suas ações.

Constata-se, pelos dados do Quadro, que as crianças do grupo A (experimental) apresentaram mudanças, sobretudo quanto a se mostrarem mais sossegadas, reflexivas, relaxadas, dinâmicas, rápidas, atentas e participativas, durante a realização das atividades de arteterapia em relação ao material de arte. No que se refere à avaliação final do grupo B (controle), este teve seu repertório comportamental de entrada (avaliação inicial) parecido com seu repertório comportamental de saída (avaliação final).
Salienta-se a diferença positiva do grupo A (experimental), após intervenções de arteterapia e enfatiza que as oficinas de arte são espaços que propiciam alívio de tensões, por favorecerem a expressão do momento de vida do indivíduo, facilitarem um encontro consigo mesmo e por ampliarem seu contato com a realidade ${ }^{(16)}$.

Concordando com estas afirmações, outro pesquisador $^{(19)}$ notara que a arteterapia auxilia, sobremaneira, tanto na elaboração da auto-expressão do indivíduo, como na de conteúdos internos (sentimentos, emoções, lembranças etc) e alívio de tensões. A expressão artística tende a ser extremamente importante e facilitadora na elaboração de conteúdos internos difíceis e delicados, geradores de conflitos $^{(20)}$.

Além destes autores, outra arteterapeuta igualmente relata que, no contexto da expressão criativa que propicia a descoberta do significado de eventos psíquicos até então obscuros, amplia-se a possibilidade de estruturação da personalidade e constroem-se maneiras mais produtivas para a comunicação, interação e o estarno-mundo ${ }^{(21)}$.

No tocante à arte, outro pesquisador ${ }^{(16)}$ refere que está é um meio de expressão, comunicação e linguagem, pois além de ser terapêutica sob diversas formas, o simples fato de o indivíduo se expressar plasticamente já é uma catarse. Através da arte podese, também, aliviar a tensão e o estresse, como uma forma de dizer coisas não aceitas socialmente. A arteterapia, mais que uma profissão, é um compromisso com a vida, um resgate da saúde pela liberdade de expressão(22).

A arte tornou-se uma forma apropriada para desenvolver na criança a independência, a curiosidade, a imaginação, a criatividade, a iniciativa e a liberdade ${ }^{(23)}$.

\section{CONSIDERAÇÕES FINAIS}

Como se sabe, a hospitalização pode se constituir em obstáculo ao desenvolvimento psicossocial normal das crianças e, assim, frente ao exposto, considera-se que o trabalho de arteterapia junto às crianças hospitalizadas torna-se fundamental para amenizar os efeitos negativos da doença, da hospitalização e do tratamento que tanto ameaçam o seu desenvolvimento normal.

As aquisições exibidas pelo grupo A (experimental), que passou pelas intervenções de arteterapia, confirmam os resultados dos estudos ${ }^{(3,24-25)}$ realizados em hospitais pediátricos de Los Angeles (EUA), Goiânia e São Paulo, respectivamente. Os autores sinalizam que, ao possibilitarem o contato das crianças com as técnicas e materiais de arteterapia, 
verificaram que as mesmas podem vivenciar de forma menos sofrida e angustiante a internação, pois a arteterapia propicia mudanças no seu campo afetivo e emocional, melhorando o equilíbrio emocional, ao término das sessões.

A arteterapia é, pois, um excelente meio para canalizar, de maneira positiva, as variáveis do desenvolvimento da criança hospitalizada e neutralizar os fatores negativos de ordem afetiva que, naturalmente, surgem com o adoecer e a hospitalização, como: estresse, angústia, agressividade e apatia; agindo preventivamente no sentido de evitarem a instalação de algumas disfunções que venham atrapalhar seu crescimento normal.

Os fatores ambientais quando estimulantes ao desenvolvimento da criança serão positivos; quando não, podem comprometê-lo ${ }^{(6)}$. Esse fato explica, em parte, a razão pela qual as crianças do grupo B (controle) apresentaram unifor-

\section{REFERÊNCIAS}

(1) Silva MJP. Comunicação tem remédio: a comunicação nas relações interpessoais em saúde. $6^{\mathrm{a}}$ ed. São Paulo: Gente; 1996.

(2) Philippini A. Mas o que é mesmo Arte Terapia? Imagens Transform: Rev Arteterapia. 1998;5(5):4-9.

(3) Valladares ACA. Arte-terapia no contexto hospitalar pediátrico. Arte-terapia: Reflex. 2000/2001;5(4):20-5.

(4) Whaley LF, Wong DL. Enfermagem pediátrica: elementos essenciais à intervenção efetiva. $2^{\mathrm{a}}$ ed. Rio de Janeiro: Guanabara Koogan; 1989.

(5) Angerami-Camon VA. Psicologia hospitalar: teoria e prática. São Paulo: Pioneira; 2002.

(6) Dias RR, Baptista MN, Baptista ASD. Enfermaria de pediatria: avaliação e intervenção psicológica. In: Baptista MN, Dias RR, organizadores. Psicologia hospitalar: teoria, aplicação e casos clínicos. Rio de Janeiro: Guanabara Koogan; 2003. p. 53-73.

(7) Cagnin ERG, Liston NM, Dupas G. Representação social da criança sobre o câncer. Rev Esc Enferm USP. 2004;38(1):51-60.

(8) Sigaud CHS, Veríssimo MOR. Enfermagem pediátrica: o cuidado de enfermagem à criança e ao adolescente. São Paulo: EPU; 1996.

(9) Brasil. Ministério da Saúde. Conselho Nacional da Saúde. Resolução 196/96. Diretrizes e normas regulamentadoras de pesquisa envolvendo seres humanos. Brasília; 1996.

(10) Machado VLS, Figueiredo MAC, Selegato V. Caracterização do desempenho do aluno em sala de aula através de escalas de desempenho. Estud Psicol. 1989;1:50-6.

(11) Siegel S. Estatística não-paramétrica: para as ciências do comportamento. São Paulo: MgGraw-Hill; 1975.

(12) Fernandes MB, Nogueira CR, Lázaros EA. Criatividade e o terapeuta. Arte-terapia: Reflex. 1995;1:14-7.

(13) Urrutigaray MC. Arteterapia: a transformação pessoal pelas imagens. Rio de Janeiro: WAK; 2003. midade ou diminuição de escores na comunicação não-verbal na avaliação final, em relação à avaliação final.

A criança, durante seu desenvolvimento normal, explora e interage com seu meio, de forma contínua, quando lhe são oferecidas oportunidades em ambientes considerados favoráveis. Portanto, cuidar de quem se encontra fragilizado e internamente desorganizado em função de uma doença grave não é tarefa fácil, e cabe ao enfermeiro/ou outro profissional arteterapeuta, que é um facilitar do processo da criança, propiciar um espaço não-ameaçador, que facilite as trocas da criança com esse ambiente.

Ademais, este estudo contribui para o avanço do conhecimento na área de avaliação do comportamento infantil, permitindo avaliar com melhor precisão as mudanças da expressão do pensamento e sentimentos das crianças, após as intervenções de arteterapia.
(14) Soares MRZ. A criança hospitalizada: análise de um programa de atividades preparatórias para o procedimento médico de inalação [tese]. São Paulo: Instituto de Psicologia da USP; 2002.

(15) Lindquist I. A criança no hospital: terapia pelo brinquedo. São Paulo: Página Aberta; 1993.

(16) Amaral MTC. A arte significando vivências de médicos que cuidam e crianças com câncer [dissertação]. Ribeirão Preto: Faculdade de Filosofia Ciências e Letras de Ribeirão Preto USP; 2002.

(17) Campos R. Cura pela arte. Viver Psicol. 1999;83:20-6.

(18) Pain S, Jarreau G. Teoria e prática da arte-terapia: a compreensão do sujeito. $2^{\mathrm{a}}$ ed. Porto Alegre: Artes Médicas; 2001.

(19) Valladares ACA, organizadora. Arteterapia no novo paradigma de atenção em saúde mental. São Paulo: Vetor; 2004. A arteterapia e a reabilitação psicossocial das pessoas em sofrimento psíquico; p. 11-3.

(20) Allessandrini CD, organizadora. Tramas criadoras na construção do ser si mesmo. São Paulo: Casa do Psicólogo; 1999. Alquimy Art: espaço de construção. Cap. 1, p. 19-30.

(21) Philippini, A. Cartografias da coragem: rotas em arteterapia. $3^{\mathrm{a}}$ ed. Rio de Janeiro: WAK; 2004.

(22) Osório V. Conversas em arteterapia. Imagens transform: Rev Arteterapia. 1997;4(4):80-91.

(23) Francisquetti AA. O museu e a criança deficiente: o toque revelador. Rev Arte-terapia: Reflex. 1995;1:1-63.

(24) Sundaram R. Art therapy with a hospitalized child. Am J Art Therapy. 1995;34(1):2-8.

(25)Alberto CM, Cabral SJ. Ateliê de arte-terapia para crianças hospitalizadas em instituição pública. In: Anais do $5^{\circ} \mathrm{Con}-$ gresso Brasileiro de Arteterapia; 2002 nov. 29-dez. 2001; Ouro Preto. [CD-ROM] Belo Horizonte: Integrante; 2002. 


\section{Anexo 1}

Ficha de Avaliação de Características de Comportamento das Crianças, em relação à Arteterapeuta*

Nome da criança:

Grupo em Estudo:

( ) Experimental

Idade:
( ) Controle

Sexo: ( ) F ( ) M

$\mathrm{DN}: \quad \ldots . . / \ldots . . . . . . .$.

Período:

anos

Avaliação: ( ) Inicial ( ) Final

a) Classifique o paciente nas escalas abaixo julgando como ele se comporta em relação à Arteterapeuta:

\begin{tabular}{|c|c|c|c|c|c|c|c|c|}
\hline $\begin{array}{l}\text { Desempenho } \\
\text { Nível (A) }\end{array}$ & $\begin{array}{l}\text { Nível } \\
\text { (A) } \\
+3\end{array}$ & $\begin{array}{c}\text { Tendência } \\
\text { para (A) } \\
+2\end{array}$ & $\begin{array}{c}\text { Leve } \\
\text { Tendência } \\
\text { para (A) } \\
+1\end{array}$ & $\begin{array}{c}\text { Não } \\
\text { pertence } \\
\text { nem (A) } \\
\text { nem (B) } \\
0\end{array}$ & $\begin{array}{c}\text { Leve } \\
\text { Tendência } \\
\text { para (B) } \\
-1\end{array}$ & $\begin{array}{c}\text { Tendência } \\
\text { para (B) } \\
-2\end{array}$ & $\begin{array}{l}\text { Nível } \\
\text { (B) } \\
-3\end{array}$ & $\begin{array}{l}\text { Desempenho } \\
\text { Nível (B) }\end{array}$ \\
\hline $\begin{array}{l}\text { 1.A)Agressivo } \\
\text { 2.A)Provocativo } \\
\text { 3.A)Desrespeitoso } \\
\text { 4.A)Desobediente } \\
\text { 5.A)Arredio } \\
\text { 6.A)Rebelde } \\
\text { 7.A)Tenso } \\
\text { 8.A)Saliente } \\
\text { 9.A)Dependente } \\
\text { 10.A)Explosivo }\end{array}$ & & & & & & & & $\begin{array}{l}\text { 1.B)Não agressivo } \\
\text { 2.B)Tranqüilo } \\
\text { 3.B)Respeitoso } \\
\text { 4.B)Obediente } \\
\text { 5.B)Comunicativo } \\
\text { 6.B)Solícito } \\
\text { 7.B)Relaxado } \\
\text { 8.B)Tímido } \\
\text { 9.B)Independente } \\
\text { 10.B)Controlado }\end{array}$ \\
\hline
\end{tabular}

* Adaptação ao Modelo de Machado, Figueiredo e Selegato ${ }^{(10)}$

\section{Anexo 2}

Ficha de Avaliação de Características de Comportamento das Crianças, em relação ao Material*

Nome da criança:

Grupo em Estudo:

( ) Experimental

Idade:
( ) Controle anos

$$
\text { Sexo: ( ) F ( ) M }
$$

Data: ..../..../.... Período:
Avaliação:
( ) Inicial
( ) Final

a) Classifique o paciente nas escalas abaixo julgando como ele se comporta em relação ao material:

\begin{tabular}{|c|c|c|c|c|c|c|c|c|}
\hline $\begin{array}{l}\text { Desempenho } \\
\text { Nível (A) }\end{array}$ & $\begin{array}{c}\text { )Nível } \\
\text { (A) } \\
+3\end{array}$ & $\begin{array}{c}\text { Tendência } \\
\text { para }(\mathrm{A}) \\
+2\end{array}$ & $\begin{array}{c}\text { Leve } \\
\text { Tendência } \\
\text { para (A) } \\
+1\end{array}$ & $\begin{array}{c}\text { Não } \\
\text { pertence } \\
\text { nem (A) } \\
\text { nem (B) } \\
0\end{array}$ & $\begin{array}{c}\text { Leve } \\
\text { Tendência } \\
\text { para (B) } \\
-1\end{array}$ & $\begin{array}{c}\text { Tendência } \\
\text { para (B) } \\
-2\end{array}$ & $\begin{array}{l}\text { Nível } \\
\text { (B) } \\
-3\end{array}$ & $\begin{array}{l}\text { Desempenho } \\
\text { Nível (B) }\end{array}$ \\
\hline $\begin{array}{l}\text { 1.A)Inquieto } \\
\text { 2.A)Impulsivo } \\
\text { 3.A)Desordeiro } \\
\text { 4.A)Vadio } \\
\text { 5.A)Tenso } \\
\text { 6.A)Saliente } \\
\text { 7.A)Apático } \\
\text { 8.A)Lento } \\
\text { 9.A)Desatento } \\
\text { 10.A)Desinteressado } \\
\text { 11.A)Retraído } \\
\text { 12.A)Confuso } \\
\text { 13.A)Não persistente } \\
\text { 14.A)Descuidado }\end{array}$ & & & & & & & & $\begin{array}{l}\text { 1.B)Sossegado } \\
\text { 2.B)Reflexivo } \\
\text { 3.B)Ordeiro } \\
\text { 4.B)Aplicado } \\
\text { 5.B)Relaxado } \\
\text { 6.B)Discreto } \\
\text { 7.B)Dinâmico } \\
\text { 8.B)Rápido } \\
\text { 9.B)Atento } \\
\text { 10.B)Interessado } \\
\text { 11.B)Participativo } \\
\text { 12.B)Orientado } \\
\text { 13.B)Persistente } \\
\text { 14.B)Cuidadoso }\end{array}$ \\
\hline
\end{tabular}

* Adaptação ao Modelo de Machado, Figueiredo e Selegato ${ }^{(10)}$

Esta pesquisa foi financiada pelo CNPQ, vinculada ao Núcleo de Estudos e Pesquisa em Saúde Integral (NEPSI)/ Faculdade de Enfermagem/ UFG. 